\title{
The Effect of Different Cavity Disinfectants on Microleakage and Interfacial Micromorphology of Class V Resin Composite Restorations Using Two Adhesive Systems (SEM-Study)
}

\author{
Ebtsam E. Kassab $^{(1)}$, Maha A. Niazy ${ }^{(2)}$, Mohammed A. El-Yasky ${ }^{(3)}$
}

Codex : 58/1810

azhardentj@azhar.edu.eg

http://adjg.journals.ekb.eg

\section{KEYWORDS}

Silver nanoparticles,

Ozone,

Microleakage.

\begin{abstract}
Purpose: This study was designed to evaluate and compare the effect of different cavity disinfectants on microleakage and interfacial micromorphology of class $\mathrm{V}$ resin composite restorations using two adhesive systems. Materials and Methods: Thirty six freshly extracted sound maxillary human premolar teeth were selected. Seventy two standardized class $\mathrm{V}$ cavities were prepared on both buccal and lingual surfaces of the selected premolars and randomly divided into three main groups $(n=24)$ according to the cavity disinfectant used (A): silver nanoparticles (A1), ozone (A2), both of them (silver nanoparticles and ozone) (A3). Each group was subdivided into 2 subgroups $(n=12)$ according to the type of the adhesive used (B): total-etch adhesive (B1), selfetch adhesive (B2). All cavities were restored with resin composite according to the manufacturer's instructions and subjected to thermocycling $\left(500\right.$ cycles, $\left.5^{\circ} \mathrm{C}-55^{\circ} \mathrm{C}\right)$. Ten cavities from each group were examined for microleakage. The interfacial micromorphology of the remaining 2 cavities was examined by environmental scanning electron microscope (ESEM). Data were expressed in scores. Results: There was a statistical significant difference between the different groups, where the highest leakage scores were found in the silver nanoparticles groups, followed by the combination groups ( $p \leq 0.05$ ). While the least leakage scores were found in the ozone groups. Also the highest leakage scores were more frequent in the self-etch groups as well as at the gingival margins of the restorations. Conclusions: Microleakage of class V resin composite restoration is affected by the type of cavity disinfectant; being improved by using ozone though deteriorated by using silver nanoparticles. It is better to use the total etch adhesive rather than the self-etch one.
\end{abstract}

- A paper extracted from Master thesis titled "The Effect of Different Cavity Disinfectants on Microleakage and Interfacial Micromorphology of Class V Resin Composite Restorations Using Two Adhesive Systems (SEM-Study)".

1. Dentist at Ministry of Health and Population.

2. Professor and Head of Operative Dentistry Department, Faculty of Dental Medicine for Girls, Al-Azhar University.

3. Professor of Operative Dentistry, Faculty of Dental Medicine for Girls, Al Azhar University and Dean of the Faculty of Dental Medicine, Sinai University. 


\section{INTRODUCTION}

Oral microorganisms that are inadvertently left underneath restorations or those invading through microgaps between the restoration and the tooth, may induce not only secondary caries, but also damage the pulp. Therefore, antimicrobial treatment before restoration could be beneficial for the success of a restoration ${ }^{(1)}$. Two different bulk fill restoration materials were evaluated in Class $\mathrm{V}$ cavities disinfected by ozone gas in terms of microleakage. It was found that, applying ozone gas as a cavity disinfectant didn't affect Microleakage ${ }^{(2)}$. The antibacterial activity of silver nanoparticles and their synthesis by chemical reduction method were studied. It was found that, the nanoparticles of silver showed high antimicrobial and bactericidal activity against gram positive bacteria ${ }^{(3)}$. One of the major threats to the long-term success of resin restorations is microleakage. The microleakage of a pit and fissure sealant containing silver nanoparticles (AgNPs) were evaluated. It was found that, the addition of AgNPs does not affect the microleakage of the sealant ${ }^{(4)}$. Two different classes of adhesives are currently used: Etch-and-rinse adhesives and selfetching adhesives. A study was held to analyze the interfacial micro morphology of total-etch and selfetch adhesives using scanning electron microscopy. The results of this study suggested that, total-etch adhesives bond better with sound dentin than selfetch adhesives ${ }^{(5)}$.

\section{MATERIALS AND METHODS}

Thirty-six freshly extracted sound maxillary human premolar teeth extracted for orthodontic purpose from an age group of 18-30 years were collected. Seventy-two standardized round class V cavities were prepared on both buccal and lingual surfaces of the selected premolars $1 \mathrm{~mm}$ coronal to the cemento-enamel junction using round bur size \#023 (Komet, Lemgo, Germany), with high speed hand piece (W\&H, Austria) under water coolant, the depth of the cavity was $2 \mathrm{~mm}$. No bevels were made at any of the enamel margins of the prepared cavities. The prepared teeth were stored in saline at room temperature $\left(23 \pm 1^{\circ} \mathrm{c}\right)$ until being used within 1 month.

\section{Samples grouping:}

Cavities were divided into 3 main groups (24 cavities each) according to the cavity disinfectant used (A): silver nanoparticles (A1), ozone (A2), both of them (A3). Each group was subdivided into 2 subgroups (12 cavities each) according to the type of the adhesive used (B): total-etch adhesive (B1), self-etch adhesive (B2). Ten cavities from each subgroup were examined for microleakage. The interfacial micromorphology of the remaining 2 cavities was examined by environmental scanning electron microscope (ESEM).

\section{Preparation and characterization of silver nanoparticles}

Silver nanoparticles were prepared by chemical reduction method. They were prepared by microwave irradiation of silver nitrate $\left(\mathrm{AgNO}_{3}\right)$ solution in ethanolic medium using PVP (polyvinyl pyrrolidone) as a stabilizing agent. Ethanol was observed to act as a reducing agent in the presence of microwave oven (SHARP, model: R-259). The concentration of the resultant solution was $107 \mu \mathrm{g} /$ ml. It was diluted in ethanol solution till it reached $50 \mu \mathrm{g} / \mathrm{ml}^{(6)}$. Monitoring of the formation of silver nanoparticles was done using Visible Near InfraRed (VIS-NIR) absorption spectroscopy. Size, shape, and particles distribution were recorded by using JEOL JEM-2100 high resolution transmission electron microscope (TEM) (Tokyo, Japan) at an accelerating voltage of $200 \mathrm{kV}$. The TEM micrographs clearly showed that, the prepared silver NPs had spherical shape and size ranging between $10 \pm 5 \mathrm{~nm}$.

\section{Cavity disinfection procedures}

Group (A): Silver nanoparticles solution was applied on the dentin surface using a fully saturated 
disposable micro-brush, left for 30 seconds and then gently air-dried for 5 seconds to allow the ethanol to evaporate ${ }^{(7)}$. Group (B): Each cavity was subjected to gaseous ozone at a concentration of $2100 \mathrm{ppm}$ $+/-5 \%$ and a flow rate of $615 \mathrm{~cm} 3 /$ minute for 60 seconds. The ozone gas was generated by an ozone generator system (Ozonita 1). Ozonita 1 was designed for the sake of ozone generation with high efficiency and controlled concentration.

\section{Restorative procedures:}

Two adhesive systems were applied according to the manufacturer's instructions [A total-etch adhesive system (Adper single bond 2) and a selfetch adhesive system (Single bond universal)]. Scotchbond тм Etchant gel was used to etch the enamel and dentin before the application of the total etch adhesive (Adper single bond 2). Both adhesives were light cured for 10 seconds using LED Light Curing Unit according to manufacturer's instructions. Resin composite was applied into the prepared cavities that were bulk-filled and light cured for 20 seconds using LED Light Curing Unit.

The specimens were subjected to 500 cycles between $5^{\circ} \mathbf{C}$ (the low-temperature point) and $55^{\circ} \mathbf{C}$ (The high-temperature point). Dwell times were 30 seconds in each water bath with a lag time $10 \mathrm{sec}-$ onds ${ }^{(8)}$.

\section{Microleakage assessment:}

Ten cavities (five teeth) from each group were examined for microleakage. The apex of each tooth was sealed by wax and the surface of each tooth (except for $1 \mathrm{~mm}$ around the restoration margin) was covered with two layers of nail polish (Max Factor, France). Then, specimens were immersed in a solution of $2 \%$ methylene blue dye (Supreme organization for drugs, Germany) for 24 hours at room temperature ${ }^{(9)}$. Subsequently, the teeth were taken out of the dye solution and washed with water. The teeth were sectioned bucco-lingually with a low speed diamond saw (Top Dent, Edenta Golden, Swiss) under water spray.
The specimens were rinsed under running water and then dried with tissue paper. The dye penetration along the cavity wall (including both occlusal and gingival margins) was assessed with a measuring Stereomicroscope (Nikon Eclips E600, Tokyo, Japan) at 45x magnification. Microleakage evaluation was performed according to the scoring system $[0=$ No dye penetration, $1=$ Dye penetration through the cavity margin reaching the enamel, $2=$ Dye penetration through the cavity margins reaching the dentin (beyond the dentino-enamel junction), 3=Dye penetration through the cavity margin reaching the cavity floor (axial wall)] ${ }^{(10)}$. Results were collected, recorded, tabulated and statistically analyzed.

\section{Environmental Scanning Electron Microscope (ESEM):}

The interfacial micromorphology of the remaining two cavities (one tooth) from each group was examined by using the ESEM. The teeth were sectioned bucco-lingually with a low speed diamond saw under water spray to be ready for the examination. The magnification used was 2000x.

Data were expressed in scores and statistically analyzed.

\section{RESULTS}

\section{Microleakage results: (table 1 and 2)}

The highest leakage scores were found in the silver nanoparticles groups (A1), followed by the combination groups (A3). While the least leakage scores were found in the ozone groups (A2). There was a significant difference ( $\mathrm{p} \leq 0.05$ ) between the different types of cavity disinfectants.

(Scores 0\&1) were more frequent in the total etch group (B1), denoting less leakage while (scores $2 \& 3$ ) were more frequent in the self-etch group (B2) denoting more leakage. There was a significant difference ( $\mathrm{p} \leq 0.05)$ between total etch (B1) and selfetch (B2) subgroups. 
(Scores 0\&1) were more frequent in the occlusal margin, denoting less leakage while (scores 2\&3) were more frequent in the gingival margin denoting more leakage. There was a significant difference $(\mathrm{p} \leq 0.05)$ between the occlusal and gingival margins .

\section{Environmental scanning electron microscope (ESEM) results:}

Tracing the interface in the silver nanoparticles/ total-etch adhesive group (A1B1) revealed a thin uniform hybrid layer that appeared with long, thin and numerous dentin resin tags. No lateral branching was observed, while in the silver nanoparticles/selfetch adhesive group (A1B2) revealed a thin uniform hybrid layer that appeared with few and thin dentin resin tags. No lateral branching was observed .

Tracing the interface in the ozone/total-etch adhesive group (A2B1) revealed a thin uniform hybrid layer that appeared with thin long and numerous dentin resin tags some of them extended to a very long distance. Multiple lateral branching was observed, while in the ozone/self-etch adhesive group (A2B2) revealed a thin less uniform hybrid layer that appeared with thin and numerous dentin resin tags of variable lengths. No lateral branching was observed.

Tracing the interface in the combination/totaletch adhesive group (A3B1) revealed thin uniform hybrid layer that appeared with numerous slightly thicker dentin resin tags of variable lengths. No lateral branching was observed, while in the combination/self-etch adhesive group (A3B2) revealed thin uniform hybrid layer that appeared with less number of slightly thicker dentin resin tags of variable lengths. No lateral branching was observed.

Table (1): Scores and significance test for the effect of the cavity disinfectant type (A) in the total etch adhesive groups (B1) for both the occlusal and gingival margins.

\begin{tabular}{|c|c|c|c|c|}
\hline Cavity margin & Score & $\begin{array}{c}\text { A1B1 } \\
\text { (Silver nanoparticles) }\end{array}$ & $\begin{array}{c}\text { A2B1 } \\
\text { (Ozone) }\end{array}$ & $\begin{array}{c}\text { A3B1 } \\
\text { (Combination) }\end{array}$ \\
\hline \multirow{6}{*}{ Occlusal } & Score 0 & 10 & 18 & 17 \\
\hline & Score 1 & 1 & 2 & 0 \\
\hline & Score 2 & 2 & 0 & 1 \\
\hline & Score 3 & 7 & 0 & 2 \\
\hline & Chi square & \multicolumn{3}{|c|}{15.2} \\
\hline & $P$ value & \multicolumn{3}{|c|}{$0.0188 *$} \\
\hline \multirow{6}{*}{ Gingival } & Score 0 & 4 & 15 & 10 \\
\hline & Score 1 & 0 & 0 & 0 \\
\hline & Score 2 & 4 & 2 & 4 \\
\hline & Score 3 & 12 & 3 & 6 \\
\hline & Chi square & \multicolumn{3}{|c|}{13.08} \\
\hline & $P$ value & \multicolumn{3}{|c|}{$0.0418 *$} \\
\hline
\end{tabular}

*significant at $p<0.05$ 
Table (2): Scores and significance test for the effect of the cavity disinfectant type (A) in the self-etch adhesive groups (B2) for both the occlusal and gingival margins.

\begin{tabular}{|c|c|c|c|c|}
\hline Cavity margin & Score & $\begin{array}{c}\text { A1B2 } \\
\text { (Silver nanoparticles) }\end{array}$ & $\begin{array}{c}\text { A2B2 } \\
\text { (Ozone) }\end{array}$ & $\begin{array}{c}\text { A3B2 } \\
\text { (Combination) }\end{array}$ \\
\hline \multirow{6}{*}{ Occlusal } & Score 0 & 3 & 11 & 3 \\
\hline & Score 1 & 3 & 2 & 4 \\
\hline & Score 2 & 0 & 2 & 1 \\
\hline & Score 3 & 14 & 5 & 12 \\
\hline & Chi square & \multicolumn{3}{|c|}{14.52} \\
\hline & $P$ value & \multicolumn{3}{|c|}{$0.0243 *$} \\
\hline \multirow{6}{*}{ Gingival } & Score 0 & 0 & 6 & 1 \\
\hline & Score 1 & 0 & 1 & 0 \\
\hline & Score 2 & 2 & 2 & 2 \\
\hline & Score 3 & 18 & 11 & 17 \\
\hline & Chi square & \multicolumn{3}{|c|}{12.73} \\
\hline & $P$ value & \multicolumn{3}{|c|}{$0.0475^{*}$} \\
\hline
\end{tabular}

*significant at $p<0.05$

\section{DISCUSSION}

Any positive benefits for the use of cavity disinfectants would be negated if the disinfectant solution significantly increased the amount of microleakage. The total etch adhesive system used in the current study was Adper ${ }^{\mathrm{TM}}$ Single Bond $2^{(11)}$. The acid etch as a first step is useful for smear layer removal and opening the dentinal tubules for resin impregnation. It was thought that using ethanol based adhesive system may be in harmony with silver nanoparticles that is also ethanol based.

The self-etch adhesive system used in the current study was Single Bond Universal that has a very unique set of properties. In the current study Filtek $^{\mathrm{TM}} \mathrm{Z} 350 \mathrm{XT}$ was used. It is a nano filled resin composite restorative material. Due to the reduced dimension of the particles and the wide size distribution, an increased filler load can be achieved with the consequence of reducing polymerization shrinkage and increasing the mechanical properties ${ }^{(12)}$.

A 2\% solution of methylene blue dye was used, its particle size is less than that of the bacterial one $^{(13)}$. The use of environmental scanning electron microscope (ESEM) preserved the dentin characteristics as no surface treatment or film deposition as gold or carbon deposition was performed on dentin surfaces ${ }^{(14)}$.

Silver nanoparticles sizes of 9 and $11 \mathrm{~nm}$ showed the highest activity against Gram +ve and Gram -ve bacteria ${ }^{(15)}$. In spherical type, a total of 50 to $100 \mu \mathrm{g}$ of silver caused $100 \%$ inhibition of bacterial growth ${ }^{(16)}$. Silver nanoparticles are effective against Streptococcus mutans with a minimum inhibitory concentration (MIC) of $50 \mu \mathrm{g} / \mathrm{ml}^{(6)}$. The preparation was done by microwave synthesis that has the advantage of improving kinetics of the 
reaction. Ethanol is a reducing agent in the preparation of ethanol based silver nanoparticles ${ }^{(17)}$. A previous study showed that Streptococcus mutans are affected to various degrees by ozone gas with almost 100\% killing after 60 seconds of ozone application when ozone gas was delivered with a flow rate of $615 \mathrm{~cm}^{3} /$ minute and a concentration of 2100 $\mathrm{ppm}+/-5 \%{ }^{(18)}$.

The results of this study were in agreement with a previous study that showed that the least microleakage was found in the ozone treated group. The reason may be that ozone dissolves the microscopic rests of organic component in the fissure, such as bacteria and their products and produces a cleaner enamel surface and hence better adhesion of the material ${ }^{(19)}$.

It was thought that, silver nanoparticles left on the dentin surface and inside the dentinal tubules, acted as a separating medium that interfered with bonding effectiveness. However, in contrary, a previous study reported that, surface treatment with ozone may significantly decrease marginal quality in dentin. This may be due to the potential interaction between residual oxygen or oxide-related substances and resin-based materials, which might interfere with adhesion ${ }^{(20)}$.

The results of this study were in accordance with some researchers who found that the etch-andrinse adhesive system showed less microleakage than the self-etch adhesive system ${ }^{(21)}$. This may be due to the incomplete etching of enamel and dentin by the acidic monomers of the self-etch adhesives. However, in contrary to this study, previous studies concluded that there was no difference in microleakage between different bonding agents. It was suggested that the bonding effectiveness of the self-etch adhesives may result from a combined micromechanical and chemical interaction with tooth substrate. The chemical component may be able to compensate for the decreased micromechanical interlocking ${ }^{(22)}$.
Results of this study were in agreement with a study that reported that the gingival sealing was significantly poorer than the occlusal sealing. This can be related to the structure of these two walls ${ }^{(23)}$.

\section{CONCLUSIONS}

Under the conditions of the present study, the following conclusions could be delivered:

1. Microleakage of class $\mathrm{V}$ resin composite restoration is affected by the type of cavity disinfectant; being improved by using ozone though deteriorated by using silver nanoparticles.

2. Both adhesive systems failed to prevent microleakage for resin restorations particularly at the gingival margins, but it is better to use the total etch one.

3. The use of different cavity disinfectants and different adhesive systems presented obvious changes in the interfacial micromorphology of the teeth.

\section{REFERRENCES}

1. Polydorou O, Pelz K and Hahn P. Antibacterial effect of an ozone device and its comparison with two dentin-bonding systems. Eur J Oral Sci 2006; 114: 349-53.

2. Omer C, Yasemin Y, Emrullah B and Yadigar YH. The Comparison of the Microleakage of Two Different BulkFill Materials in Teeth Disinfected By Ozone Gas. Adv Dent \& Oral Health 2016; 1: 18-22.

3. Guzmán MG, Dille J, Godet S. Synthesis of silver nanoparticles by chemical reduction method and their antibacterial activity. International Journal of Chemical and Biomolecular Engineering 2009; 2:3

4. Morales E, Martínez A, Hernández J, Alvarado K and Pozos A. Evaluation of Marginal Seal and Microleakage of a Sealant Modified with Silver Nanoparticles in Primary Molars: In Vitro Study.-ODOVTOS-Int. J. Dental S.C., 2015; 16: 105-111.

5. Drobac M, Stojanac I, Ramić B, Premović M and Petrović L. Micromorphological characterization of adhesive interface of sound dentin and total-etch and self-etch adhesives. Med Pregl 2015; LXVIII (1-2): 10-16. 
6. Besinis A, De Peralta T and Handy RD. The antibacterial effects of silver, titanium dioxide and silica dioxide nanoparticles compared to the dental disinfectant chlorhexidine on Streptococcus mutans using a suite of bioassays. Nanotoxicology. 2014; 8: 1-16.

7. Arafa H. Evaluation of silver nanoparticles as surface pretreatment on color change of resin composite restoration. Master thesis in Operative Dentistry, Faculty of Oral and Dental Medicine, Cairo University, 2013.

8. Khoroushi M, Shirban F and Mahsa Samani S. Marginal integrity of low-shrinkage and methacrylate-based composite resins: Effect of three different hemostatic agents. J Clin Exp Dent. 2016; 8: e178-e83.

9. Magni E, Zhang L, Hickel R, Bossù M, Polimeni A and Ferrari M. SEM and microleakage evaluation of the marginal integrity of two types of class $\mathrm{V}$ restorations with or without the use of a light-curable coating material and of polishing. J Dent. 2008; 36:885-91

10. Masih S, Thomas AM, Koshy G and Joshi JL. Comparative evaluation of the microleakage of two modified glassionomer cements on primary molars, an in-vivo study. J Indian Soc Pedod Prev Dent 2011; 29: 135:39.

11. Guimaraes LF, Almeida J, Wang L, D’Alpino P and Garcia F. Effectiveness of immediate bonding of etch-and-rinse adhesives to simplified ethanol-saturated dentin. Braz Oral Res 2012; 26: 220-32.

12. Andrade AK, Duarte RM, Silva FB, Batista AU, Lima KC and Montes MA. Clinical trials with nanoparticle composite in posterior teeth. Braz J Oral Sci 2009; 8: 114-18.

13. Agrwal VS, Parekh VV and Shah NC. Comparative evaluation of microleakage of silorane-based composite and nanohybrid composite with or without polyethylene fiber inserts in class II restorations: an in- vitro study, J Oper Dent 2012; 37:E1-E7.

14. Collins SP, Pope RK, Scheetz RW, Ray RI, Wagner PA and Little BJ. Advantages of Environmental Scanning Electron Microscopy in Studies of Microorganisms. Micros Res Tech 1993; 25:398-05.
15. Guzmán MG, Dille H, Godet S. Synthesis of silver nanoparticles by chemical reduction method and their antibacterial activity. International Journal Chem Biom Engin 2009; 2:3.

16. Panacek A, Kolar M, Vecerova R, Prucek R, Soukupov J, Krystof V, Hama LP, Zboril R, and Kvitek L. Antifungal activity of silver nanoparticles against Candida spp. Biomat 2009; 30: 6333-40.

17. Fathy H. Microtensile bond strength of resin composite to dentin pretreated with antimicrobial nanoparticles. Master thesis in Operative Dentistry, Faculty of Oral and Dental Medicine, Cairo University, 2012.

18. Johansson E, Claesson R and van Dijken JW. Antibacterial effect of ozone on cariogenic bacterial species. J Dent 2009; 37:449-53.

19. Celiberti P, Pazera P and Lussi A. The impact of ozone treatment on enamel physical properties. Am J Dent 2006;19: 67-72.

20. Dukic W, Dukic OL and Milardovic S. The Influence of Healozone on Microleakage and Fissure Penetration of Different Sealing Materials. Coll Antropol 2009; 33: 1: 157-62.

21. Häfer M, Schneider H, Rupf S, Busch I, Fuch A, Merte I, Jentsch H, Haak R and Mert K. Experimental and clinical evaluation of a self-etching and an etch-and-rinse adhesive system. J Adh Dent. 2013; 15: 275-86.

22. El Sayed HY, Abdalla AI, Shalby ME. Marginal microleakage of composite resin restorations bonded by desensitizing one step self-etch adhesive. Tanta Dent 2014; 11: 180-8.

23. Oskoee SS, Oskoee PA, Navimipour EJ, Ajami AA, Azar FP, Rikhtegaran S and Amini M. Comparison of the effect of Nd:YAG and Diode lasers and photodynamic therapy on microleakage of Class V composite resin restorations. J Dent Res Dent Clin Dent Prospect 2013;7:74-80. 